\title{
The Character of Long-Term Abrasion of Dental Implant
}

\section{Daniela Koštialiková, Mariana Janeková, Andrej Dubec, Ing. Matej Burget, Františka Pešlová}

Faculty of Industrial Technology in Puchov, Alexander Dubcek University of Trencín, I. Krasku 491/30, 02001 Puchov, Slovakia. E-mail: daniela.kostialikova@fpt.tnuni.sk, mariana.janekova@fpt.tnuni.sk, andrej.dubec@fpt.tnuni.sk, matejburget@centrum.sk, frantiska.peslova@fpt.tnuni.sk

During the period of use, there are in the dental implants, the limit conditions of the primary structure and later on its disruption created. The aim of the work was to study microscopic defects in the proposed materials in which the unwanted defects arose and led to early end of the lifetime. It is a dental implant, which had to be prematurely taken from the oral cavity due to limit conditions of the patient pain.

Investigation of chemical elements of dental implant materials has shown the presence of such components, which lead to create undesirable intermediate phases in the structure and therefore the analysis of the implants has been complemented by microscopic evaluation.

There are on the part of the dental implant, which interacts with a bone of a patient, the corrosion destruction of the material was visually observed. For this reason, the character and thickness of oxide layer, that negatively affects the living cells of the organism, was also examined on more detail.

Keywords: Dental replacement, Biocompatibility, Microstructure, Corrosion, Titanium

\section{Introduction}

Dental replacements consist of composite connection of several materials. These materials are represented by pure metals, alloys of non-ferrous metals, steel and ceramics. In the case that one of material is damaged, a chain reaction of ongoing degradations may occur in other implant units of composite that are in connection with the affected part. A similar problem was observed in the case a patient whom a part of dental replacement was loosen in the bone. During the loading (i. e. eating and chewing) it was not fixed and caused the pressure to the bone. This has resulted in a limiting state leading to material wear and therefore, there was a malfunction of the implant, with the subsequent limiting state of the deformation of bone in which the implant was placed and it was the reason for patient's pain.

The aim of this work was based on the microscopic study of the materials for the dentals replacement and determination of whole dysfunction. Moreover, it can help to identify other undesirable effects that can cause pain to a patient. Since no information was available on the manufacture and composition of the dental replacement, the procedure of the analysis was based on the facts obtained from microstructures of the dental replacement. For each metallographically prepared microstructure, a chemical analysis of the elements was carried out so then a particular material was assigned to the chemical composition. The experiment was aimed at identifying of limiting states in specific materials that represented the dental replacement.

\section{Experiment}

The dental replacement consists of the three components: crown, the abutment and the implant. The attention is paid to all elements of replacement, using the light and electron microscopy. A wear of the material has already been visually observed on the part of the dental replacement, which was in interaction with the patient's bone after its removal from the oral cavity. The surface of this part was very rough and oxidized. The tooth construction was cut cross two teeth (see Fig. 1a) as well as perpendicularly (Fig. 1b, c) in order to study of the microstructure of all the materials used in the dental replacement.

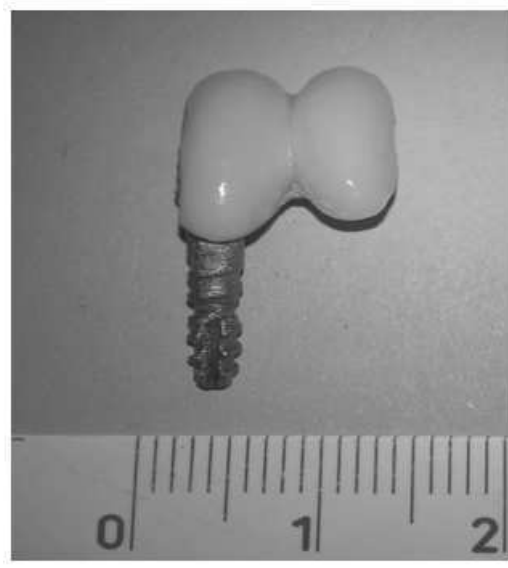

a

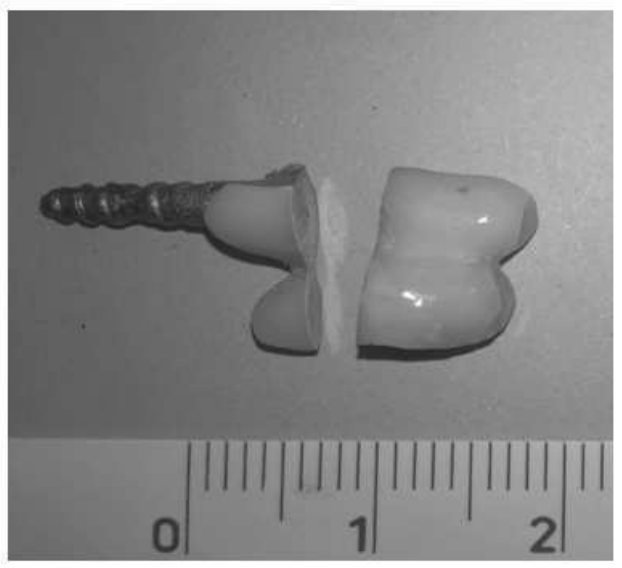

b

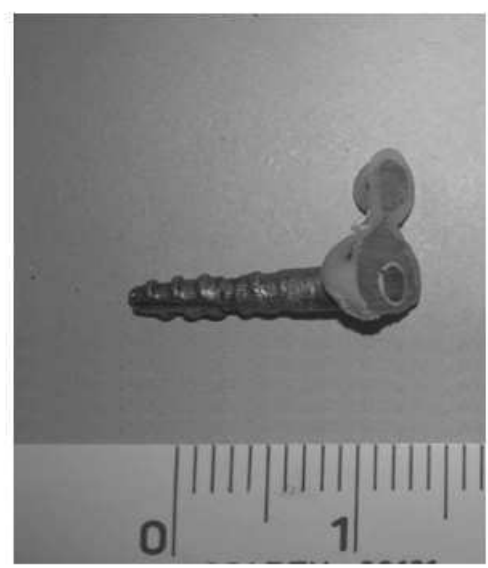

c

Fig. 1 Preparation of individual parts for microscopic evaluation 
Before and during the microstructure investigation, a chemical composition was analysed at all available locations. The analysis was performed with the EDX detector: X-act; Oxford Instruments and the EDX-7000 Shimadzu X-ray Fluorescence Energy Dispersion Spectrometer. In order to obtain information about the individual materials used in the dental replacement, the weight percentage of the individual elements was taken as basis for their identification. The elements, which specify the alloy, are shown in particular binary phase diagram (BPD). Based on the chemical analysis of individual materials, the binary phase diagram with the corresponding alloy was selected according to the largest content of individual elements.

\section{Chemical analysis of individual dental repla- cement materials}

The crown, abutment and implant were studied separately to obtain a large number of spectres, which were subsequently used for evaluation and determination of dental replacement materials.

The six different spectra were evaluated (Fig. 2, Fig. 3.) and the chemical analyses were carried out by means of EDX method (Tab. 1-6), where:

- Spectrum 1 - ceramics (top part of dental replacement)

- Spectrum 2 - ceramic - metal (crown) interlayer,

- $\quad$ Spectrum 3 - metal (crown),

- $\quad$ Spectrum 4 - metal (crown) - metal (abutment) interlayer,

- $\quad$ Spectrum 5 - metal (abutment),

- $\quad$ Spectrum 6 - metal (implant in bone).

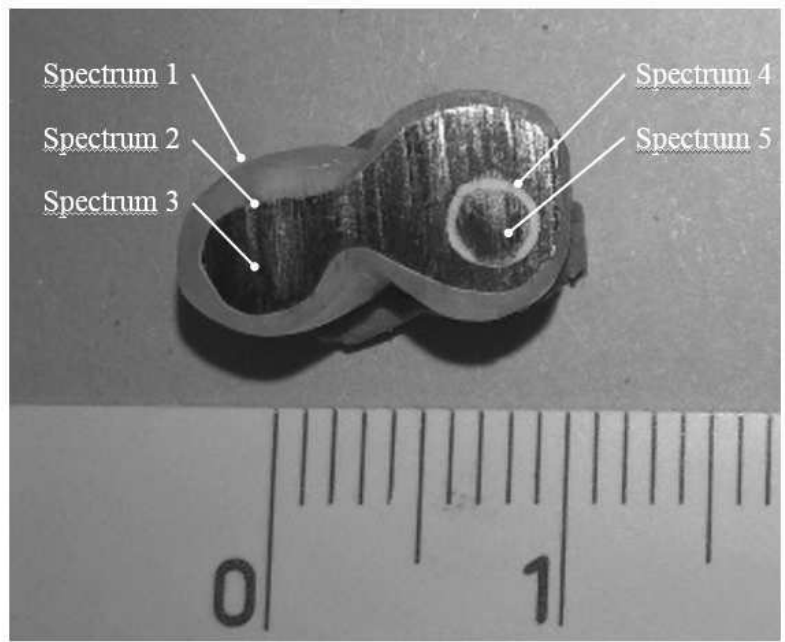

Fig. 2 Selection of locations for chemical analysis

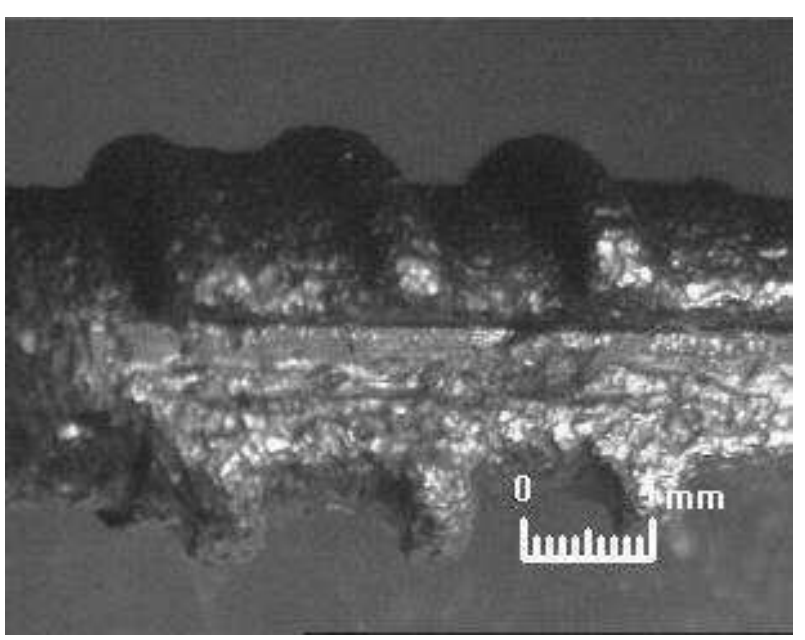

Fig. 3 Part of screw - spectrum marked as 6

Tab. 1 Chemical analysis of the ceramic part (spectrum from the places marked as 1)

\begin{tabular}{|c|c|c|c|c|c|}
\hline \multirow{3}{*}{ Spectrum 1 } & \multicolumn{5}{|c|}{ Weight \% } \\
\cline { 2 - 6 } & $\mathbf{O}$ & Na & Si & K & Bi \\
\cline { 2 - 6 } & 68.02 & 5.76 & 15.43 & 1.67 & 9.12 \\
\hline
\end{tabular}

Tab. 2 Chemical analysis of ceramic - metal (crown) interlayer, (spectrum from the places marked as 2)

\begin{tabular}{|c|c|c|c|c|c|c|c|c|c|}
\hline \multirow{3}{*}{ Spectrum 2} & \multicolumn{9}{|c|}{ Weight \% } \\
\hline & $\mathrm{C}$ & $\mathbf{O}$ & Si & $\mathbf{K}$ & $\mathrm{Ca}$ & $\mathbf{T i}$ & Zn & Ta & Au \\
\hline & 67.04 & 25.93 & 3.53 & 0.91 & 0.12 & 0.06 & 0.1 & 0.03 & 2.29 \\
\hline
\end{tabular}

Tab. 3 Chemical analysis of metal part (crown), (spectrum from the places marked as 3)

\begin{tabular}{|c|c|c|c|c|c|c|}
\hline \multirow{3}{*}{ Spectrum 3 } & \multicolumn{6}{|c|}{ Weight \% } \\
\cline { 2 - 8 } & $\mathbf{C}$ & $\mathbf{S i}$ & $\mathbf{C r}$ & $\mathbf{N i}$ & $\mathbf{M o}$ & $\mathbf{P b}$ \\
\cline { 2 - 8 } & 3.66 & 1.3 & 22.91 & 59.11 & 10.15 & 2.86 \\
\hline
\end{tabular}

Tab. 4 Chemical analysis of metal (crown) - metal (abutment) interlayer, (spectrum from the places marked as 4)

\begin{tabular}{|c|c|c|c|c|c|c|c|c|c|}
\hline \multirow{3}{*}{ Spectrum 4 } & \multicolumn{10}{c|}{ Weight \% } \\
\cline { 2 - 13 } & $\mathbf{C}$ & $\mathbf{O}$ & $\mathbf{F}$ & $\mathbf{A l}$ & $\mathbf{S i}$ & $\mathbf{P}$ & $\mathbf{K}$ & $\mathbf{C a}$ & La \\
\cline { 2 - 12 } & 23.61 & 38.76 & 11.89 & 6.05 & 5.93 & 0.98 & 0.87 & 4.06 \\
\hline
\end{tabular}

Tab. 5 Chemical analysis of metal part (abutment), (spectrum from the places marked as 5)

\begin{tabular}{|c|c|c|c|c|}
\hline \multirow{3}{*}{ Spectrum 5 } & \multicolumn{4}{|c|}{ Weight \% } \\
\cline { 2 - 5 } & $\mathbf{A l}$ & $\mathbf{T i}$ & $\mathbf{V}$ & Yb \\
\cline { 2 - 5 } & 6.89 & 92.16 & 0.8 & 0.15 \\
\hline
\end{tabular}


Tab. 6 Chemical analysis of metal (implant), (spectrum from the places marked as 6)

\begin{tabular}{|c|c|c|c|}
\hline \multirow{3}{*}{ Spectrum 6 } & \multicolumn{3}{|c|}{ Weight \% } \\
\cline { 2 - 4 } & $\mathbf{C}$ & $\mathbf{T i}$ & H \\
\cline { 2 - 4 } & 4.4 & 95.1 & 0.04 \\
\hline
\end{tabular}

Based on the chemical analysis, individual materials can be sorted and classify into standardized groups. The ceramic part of which the chewing part of the crow was made is shown in Tab 1. and it is based on silica oxide. Other elements, such as sodium and kalium of ceramic part, make the ceramic to be more compact so it is less porous. Bizmut, in technical practice, stabilizes the white colour of ceramics because is also helpful for dental purposes. The admissible percentage amount of bizmut for biomedical purposes has not been determined by the standard yet, so the given percentage of bizmut depends on each laboratory workplace.

In the metal-ceramic interlayer (Tab. 2), the material purity as well as precision of the technological process for the bonding of metallic and non-metallic material is reflected. The technical equipment of the dental laboratory and the professional skills of a laboratory worker are reflected in the quality of the interlayer, from the aspect of essential part in relation to challenging environment in which the dental replacement is mechanically loaded. The presence of other elements may serve for better adhesion or for slowing (or elimination) of the mutual diffusion of some active elements. It is likely that the gold that was present in the interlayer could act as a "neutralizer" or as a barrier to possible diffusion.

Based on the chemical composition of another part (metal part) of the dental replacement (from spectrum marked as 3, Tab. 3) it can be stated that this material corresponds to NiCrMo alloy, with the occurrence of other mostly undesirable elements, e. g. Pb. This element is not allowed to be in the alloy at all but it was detected even after multiple analyses and it means, it had to be present directly in an alloy and it could not get there during manipulation with replacement.

According to the above-mentioned spectrum (marked as 4 ), the interlayer contained a large number of different

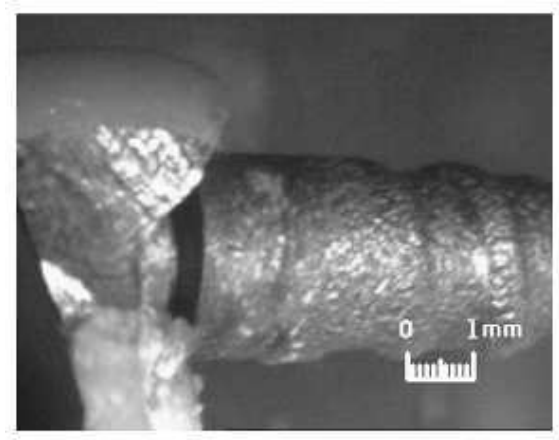

a

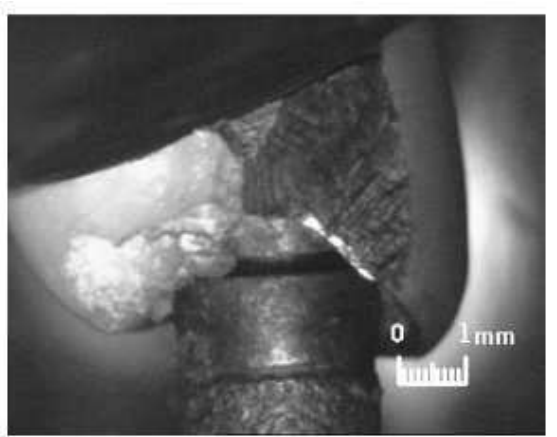

$\mathrm{b}$ elements (Tab. 4). It is not possible to unambiguously determine how these elements got into the analysed part. It is only possible to assume that it can be based on unprofessional production, lack of purity or the time interval of loosened implant usage. While the loosened implant was in motion in the gums, various food elements or toothpaste could have remained in the area between the loosened implant and gums.

According to the chemical elements (Tab. 5), analysis of material from the abutment corresponds to the Ti-6Al$4 \mathrm{~V}$ alloy (Spectrum marked as 5). This material, with its mechanical properties, is the one of the most used titanium alloys in medical practice. Some patients are at risk of allergic reactions to Al. Another problem may be based on insufficient micro purity of the alloy. The chemical analysis showed that there were also small amount of other elements in this structure that can be also described as undesirable [11,12].

The chemical composition of the implant (with screw geometry) corresponds to Grade $2 \mathrm{cpTi}$ (Spectrum marked as 6). It is a material that is also most widely used in medicine because of its biocompatibility, inertia and balanced material properties [8]. In relation to this material, it is always necessary to check the level of hydrogen because it forms hydrides that can cause disruption and embrittlement.

\section{Microscopic evaluation of the given materials}

Metallographically prepared samples were studied under the stereomicroscope at first, whereby the particular places were selected for microscopic micromorphology evaluation. The sites that shows the character and quality of the material were observed in more detailed way (Fig. 4).

Fig. 4 Details of the dental replacement ( $a$-crown verzus implant, $b$-abutment, $c-$ screw area)

From the macroscopic point of view, so-called damaged or degraded dental replacement areas were selected and subsequently, they were microscopically studied and evaluated. This article also highlights microstructures that could be significant in a certain way to create a limiting state.

\subsection{Micromorphology of alloy NiCrMo (crown)}

The microstructure of the crown material required longer etching time to highlight the pores and cavities of different sizes and shapes with random distribution. Its character corresponds predominantly to the dendritic 
phase arrangement, which is not suitable for the given material (Fig. 5). The elements forming an alloy on the base $\mathrm{Ni}, \mathrm{Cr}$, Mo have the main influence on the composition of the structure. Since no information was available on the dental alloy (dental replacement), the study of the individual phases and determination of the material was based on the chemical analysis and amount of the individual elements in materiál [13].

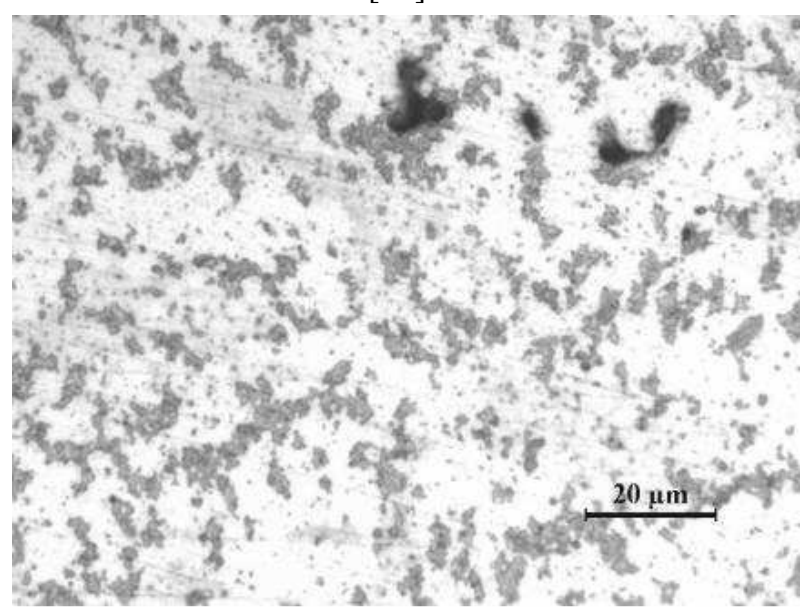

Fig. 5 NiCrMo alloy microstructure

From research sources, it is known that there is one stable $\gamma$-phase with a face centred cubic lattice over a temperature of $1250^{\circ} \mathrm{C}$. It can be estimated that at the temperature of $850^{\circ} \mathrm{C}$, the structure of the alloy will contain $60 \%$ of $\mathrm{Ni}$ in a stable phase that will be affected by alloying elements. Their distribution affects the creation of new phases. If residual elements are present in the structure during the cooling (from $1250{ }^{\circ} \mathrm{C}$ ), they will participate in the formation of carbides, or in the formation of other phases, such as the $\sigma$-phase, $\mu$-phase or $\pi$ phase. The occurrence of these undesirable phases has a significant effect on the reduction of the overall quality of the component $[3,10]$.

\subsection{Alloy Ti-6Al-4V (abutment)}

From the evaluation of the Ti-6Al-4V alloy micro purity, it can be clearly stated that the recorded occurrence of oxide and carbide phases, on the basis of vanadium and aluminium with different size and uneven distribution in the structure (Fig. 6), will negatively affect the lifetime of this component.

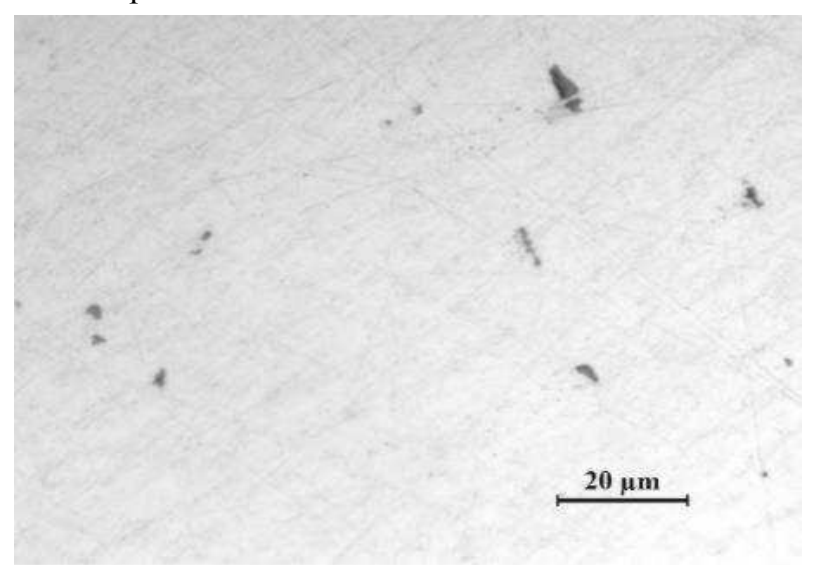

a)

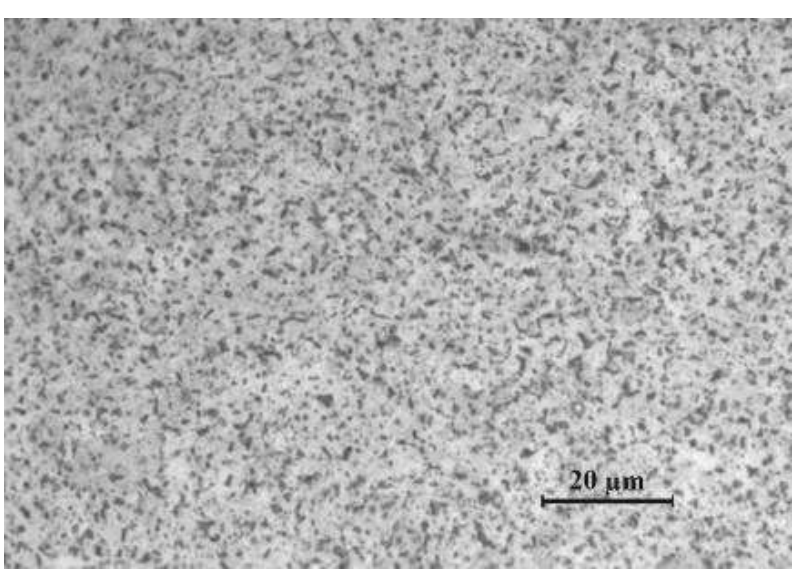

b)

Fig. 6 Microscopic evaluation of Ti-6Al-4V alloy

The Ti-6Al-4V alloy microstructure has a biphasic character and it consists of $\alpha$-phase and $\beta$-phase without significant grain boundaries. Chemical analysis has shown uneven distributions of alloying elements. The nature of the microstructure is affected by the recrystallization temperature in the $\mathrm{Ac}_{3}$ region, where globularization and formation of the $\alpha+\beta$ phase grained morphology occurs $[1,9]$.

\subsection{Material cpTi - Grade 2 (implant's screw)}

The microstructure of the material interacting with the tissue cells was evaluated both in the transverse and longitudinal sections of the titanium screw (Fig. 7) During the transformation of $\alpha$-phase into $\beta$-phase, there is a significant change in the material and it can also have effect on susceptibility of the material to oxidation. From these microstructures, it is seen that the highest susceptibility is on the grain boundary between $\alpha$-phase and $\beta$-phase. There was also a higher proportion of oxides identified $[5,8]$.

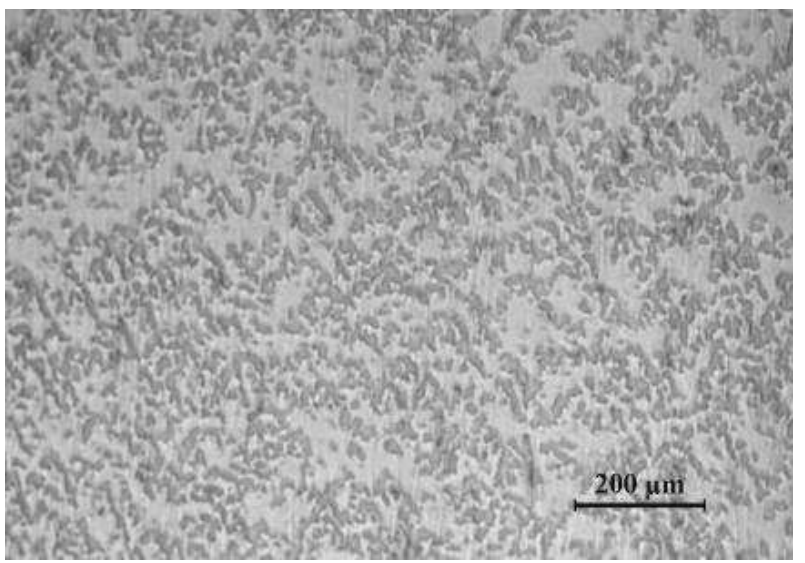

Fig. 7 Microstructure of dental implant (screw)

Using an electron microscope, it is possible to supplement the observations that could not be obtained from the light microscopy. The observed places were selected because of changes expectation in the microstructure and subsequent supposed degradation. In the given case, there was an occurrence of an oxide layer on the surface of the screw part of the implant and therefore it was investigated in more detailed way (Fig. 8). 


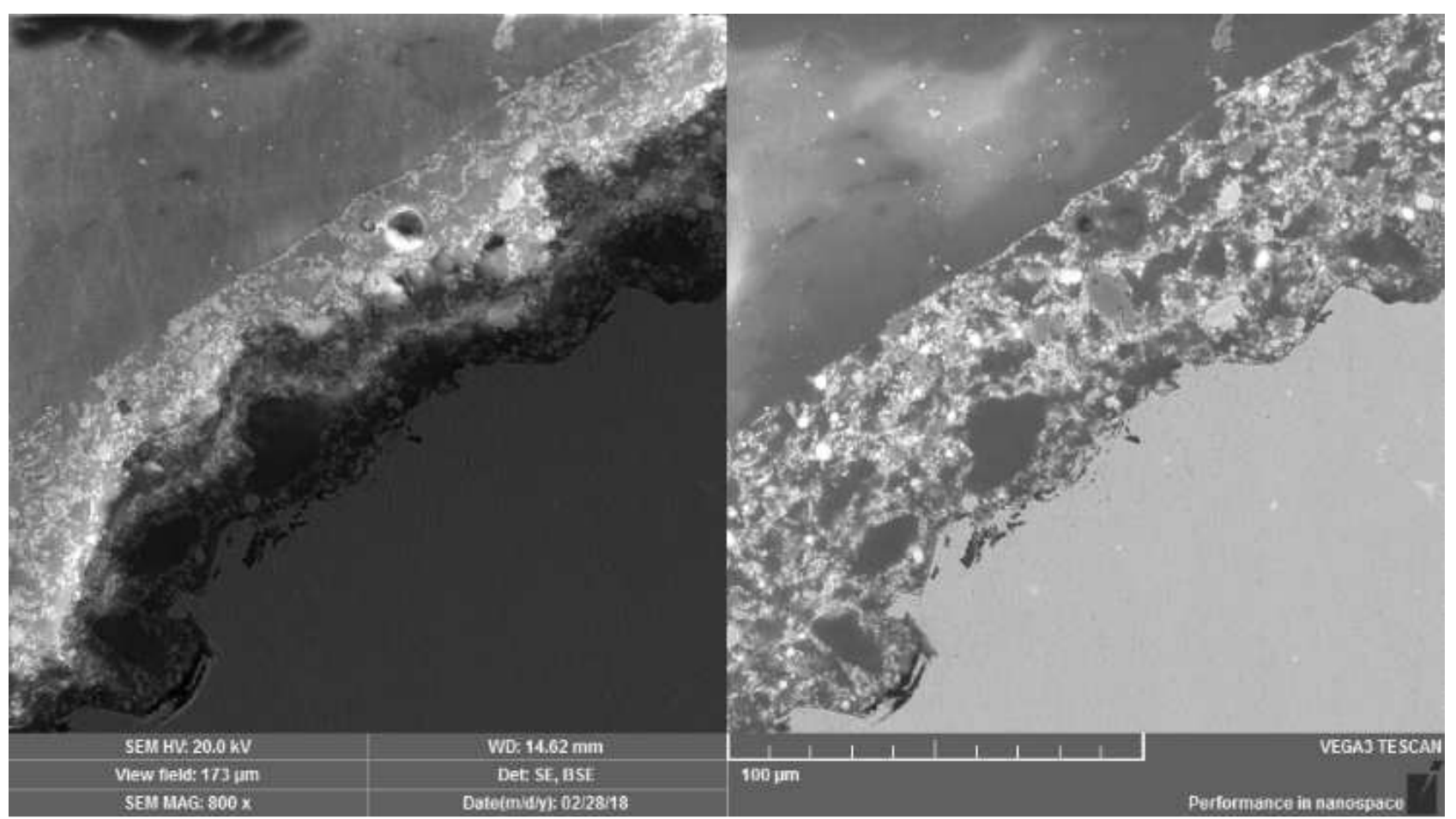

Fig. 8 Surface area with the presence of oxides

From a detailed study of these randomly selected areas, it can be stated that the surface of the alloy contains cavities of different depths and widths (Fig. 9 - 10) In this case, it is difficult to prove that the roughness imperfection of the screw surface is the result of either inadequate machining or using of the implant.

According to the nature of the corrosive attack, it is possible to state that there is uneven corrosion, which is represented by attacking only some of the surface areas of the material at different widths and depths. Attacked locations can stand for the distribution of chemical elements in a given structure or imperfect surface treatment before insertion of screw into the bone.

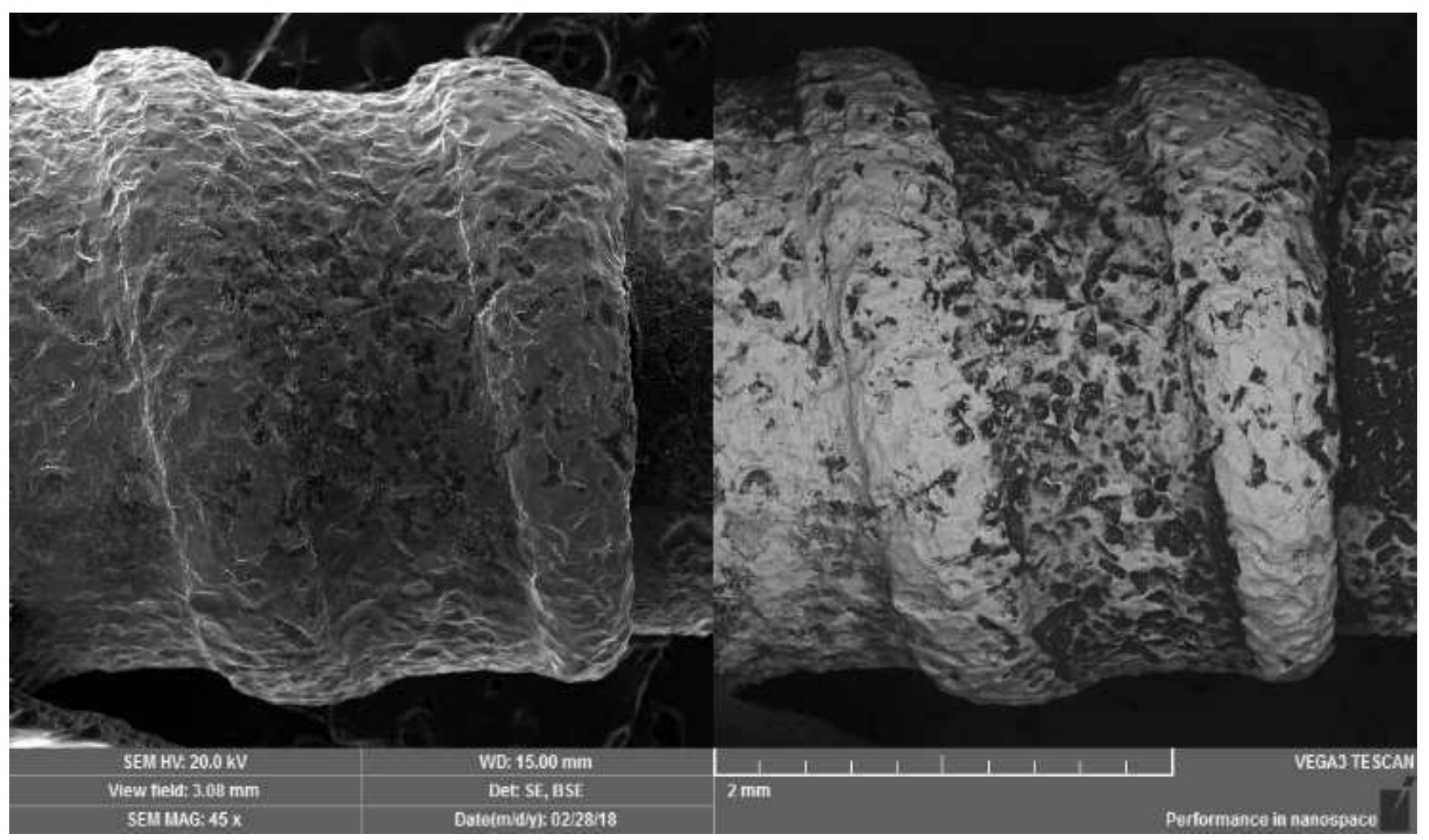

Fig. 9 Degraded screw surface 


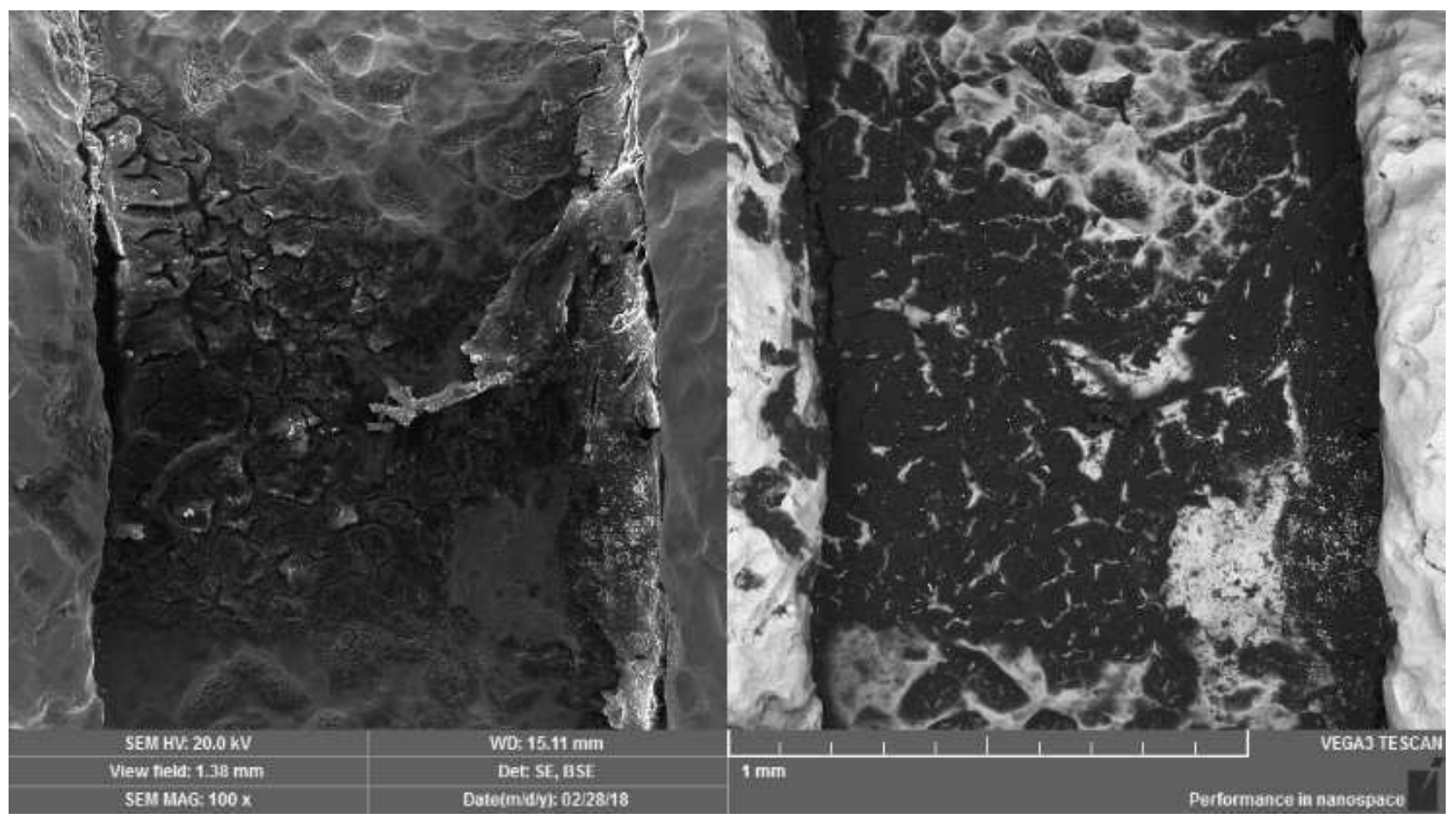

Fig. 10 Detailed image of corrosion attack

Microscopic evaluation of the screw part of the dental implant confirmed the oxide layer where the thickness of the oxides ranged from 76 to $234 \mu \mathrm{m}$. Since oxides can degrade and can be peeled from the surface, they can damage the bone cells that interacts with them. The other problem can be seen in the sedimentation of the harmful toxic surface deposits that can also cause infection in the bone. The given structure of the surface is unacceptable in the bone implant $[6,7]$.

\section{Conclusion and recommendation}

The nature of the limiting states of dental replacement resulting in wear was examined in this article. The dental implant had to be immediately removed from the oral cavity due to patient pain. For biomaterials in the function of dental replacements, it is important to monitor any change that can cause a limiting state.

From microscopic and chemical analyzes of microstructures of individual materials of the investigated dental replacement, it can be stated that a reason for the limiting states, degradation and subsequent reduction of its lifetime was found in each material. Based on the chemical composition of the individual materials, it is alarming that they also contain elements that are absolutely inadmissible (e.g. lead) from a biomaterial point of view.

The corrosive degradation of the surface of the titanium part, which interacts with the bone cells, can cause other undesirable limiting states that affect the overall health of a patient.

Based on the investigation, it can be concluded that excessive cyclical load and micromotion of the implant in the bone leads to the effect of the various $\mathrm{pH}$ environments which superpose the formation and growth of corrosive layers which can be peeled from replacement. Loosen sharp particles then violate the tissue and, when the metal part is attacked, it leads to inflammatory processes because the metal ions are actively decomposed. From scientific studies, it is known that titanium corrosion leads to implant failure or initiation of periimplantitis (a serious complication during implant medical cure, inflammatory changes in the tissue which surrounds the implant, coming up to bone loss.

The prevention from the formation of electrochemical cells in the oral cavity and the subsequent microbiological corrosion can be preserved by keeping of the titanium micro purity and the prescribed surface treatment of the metal parts of the dental replacement, leading to a smooth surface with a high brightness.

Based on the study and research of randomly selected dental replacements that had to be taken prematurely from the oral cavity, it can be stated that any unknown material can cause limiting state, which will lead to premature reduction of lifetime. Due to the fact that the dental replacement has strict geometry depending on individual patient's oral cavity, it is always laboratory piece production. Dental replacement manufacturing is based on precise and responsible approach and it means that if the manufacturer and the suppliers are not known, it is recommended to perform both chemical and microscopic analysis before using.

\section{Acknowledgement}

This paper deal was supported by the Slovak Grant Agency KEGA 007TnUAD -4/2017, VEGA grant No. 1/0649/17, VEGA grant No. 1/0589/17 and resulted from the project ,Center for quality testing and diagnostics of materials", ITMS code 26210120046 relating to the Operational Program Research and Development funded from European Fund of Regional Development. 


\section{References}

[1] SPEELMAN, J.A, COLLAERT B, KLINGE B. (1993). Evaluation of different methods to clean titanium abutments. A scanning electron microscopic study. Clinical Oral Implants Research, pp. $120-127$.

[2] BHOLA, R., BHOLA, S.M., MISHRA, B., OLSON D.L. (2011). Corrosion in Titanium Dental Implants/Prostheses - A Review, Trends Biomater. Artif. Organs, 25(1), pp. 34-46.

[3] KLIMECKA-TATAR, D.: Quality of Ni-Cr-Mo casting dental alloys in terms of $\mathrm{Ni}$ and Mo contents changing. Zeszyty Naukowe Quality. Production. Improvement No. 1(1) 2014 pp. 121-130.

[4] ADYA, N., ALAM, M, RAVINDRANATH, T., MUBEEN, A., SALUJA, B. (2005). Corrosion in titanium dental implants: literature review. $J$ Indian Prosthodont Soc, pp. 126 - 131.

[5] CHATURVEDI, T.P. (2009). An overview of the corrosion aspect of dental implants (titanium and its alloys). Indian, Journal of Dental Research, 20, pp. 91-98.

[6] AGARWAL, A., TYAGI, A., AHUJA, A., KUMAR, N., DE, N., BHUTANI, H. (2014). Corrosion aspect of dental implants - An overview and literature review. Open Journal of Stomatology. Vol.4 No.2, Article ID: 42956, 5 p.

[7] GEETHA, M., DURGALAKSHMI, D. AND ASOKAMANI, R. (2010) Biomedical implants: Corrosion and its prevention-A review. Recent Patents on Corrosion Science, 2, pp. 40 - 54.
[8] MASSARO, C., ROTOLO, P., DE RICCARDIS, F., et al. (2002) Comparative investigation of the surface properties of commercial titanium dental implants: Part I. Chemical composition. Journal of Materials Science: Materials in Medicine, 13, pp. $535-548$

[9] TAllarico, M., CANUllO, L., CANEVA, M., ÖZCAN, M. (2008). Microbial colonization at the implant-abutment interface and its possible influence on periimplantitis: A systematic review and meta-analysis. Journal of Prosthodontic Research. Volume 61, Issue 3, July 2017, pp. $233-$ 241.

[10] LIN, H.Y., BOWERS, B., WOLAN, J.T., CAI, Z., BUMGARDNER, J.D. (2008). Metallurgical, surface, and corrosion analysis of $\mathrm{Ni}-\mathrm{Cr}$ dental casting alloys before and after porcelain firing. Dental materials 24, pp. $378-385$.

[11] STANCEKOVA, D., SEMCER, J., RUDAWSKA, A., CEP, R. (2015). Identification of Drilling of Biocompatible Materials Based on Titanium. Manufacturing Technology. Volume 15 , pp. $699-704$.

[12] MARTIKAN, A., STRUHARNANSKY, J., STANCEKOVA, D., CZAN, A., HATALA, M. (2015). Influence of Chemical Etching on Surface Micro-Geometry of Titanium Implants. Manufacturing Technology. Volume 15, pp. $601-604$.

[13] ZATKALÍKOVÁ, V., MARKOVIČOVÁ, L., CHALUPOVÁ, M. (2016). Corrosion resistance of Cr-Ni-Mo Stainless Steel in Chloride and Fluoride Containing Environment. Manufacturing Technology. Volume 16, pp. 1193 - 1198. 